\title{
Nuevas anotaciones sobre «la letra cortesana», nombre dado a este tipo gráfico por la corte de Castilla *
}

\section{New Data Concerning the Cortesana script, the Name Given to This Graphic Script in the Castilian Court}

\author{
Blas CASAdo QuintaniLLA **
}

\begin{abstract}
RESUMEN
Las formas de la letra denominada «cortesana» por parte de la cancillería real del siglo XV Ilamó la atención de Enrique de

Villena; un intelectual del citado siglo que quiso buscar una explicación a las formas de algunas letras consonantes de nuestro abecedario. Atribuyó esas formas «revueltas» a una fuerte influencia de la cultura gráfica de «los moros» y a una manera concreta de cortar la pluma para trazar la escritura. Otros intelectuales castellanoleoneses de finales del siglo XV y primeros años del XVI constataron la consolidación de algunas letras nuevas y observaron otras características

relacionadas con la forma de ejecutar algunas abreviaturas, así como la incorporación de algunas letras nuevas, $y$ las pusieron por escrito en sus respectivas obras.
\end{abstract}

\section{PALABRAS CLAVE}

Enrique de Villena, Alvar Gómez de Castro, Juan de Valdés, letra «cortesana», letra «ñ» y otras, abreviaturas.

\section{ABSTRACT}

The graphic forms of the script known as "Cortesana» by the Royal Chancery in the fifteenth century caught the attention of Enrique de Villena, an intellectual of that time who attempted to find an explanation to the consonant forms of this alphabet script. He attributed the «convoluted» forms to a strong influence of Moorish culture and a certain manner of holding the quill in the process of writing. Other intellectuals from Castile and León at the end of the fifteenth and the first years of the sixteenth century witnessed the consolidation of certain new letters and observed other characteristics related to the manner of execution of the abbreviations and implemented them in their respective writings.

\section{KEY WORDS}

Enrique de Villena, Alvar Gómez de Castro, Juan de Valdés, the Castilian "Cortesana» Script, The Letter «ñ » and Others, Abbreviations.

* Fecha de recepción del artículo: 2013-11-18.

** UNED. C.e.: bcasado@geo.uned.es 
Hace algunos años publiqué unas reflexiones acerca de la forma de las letras manuscritas usadas, sobre todo en el reino de Castilla ${ }^{1}$, a lo largo de la centuria décimo quinta. Entonces los argumentos estaban pegados a un análisis detallado y minucioso de las propias formas de las letras objeto de estudio, sobre todo de las letras consonantes de nuestro abecedario de origen latino; también hicimos algunas incursiones y resaltamos la importancia de determinadas circunstancias históricas. Con posible ingenio y con posible buen juicio, buscamos entonces y encontramos algunos elementos que nos permitieron organizar unas conclusiones que si sólo hubieran sido ingeniosas estaríamos próximos al error o en el mismo error, más si fueron juiciosas nos alejaron de aquel y nos aproximaron al tan deseado buen juicio. A nuestro entender la aparición de las formas nuevas de un buen número de letras consonantes en este tipo gráfico obedece a una influencia cultural ajena a nuestra cultura latina; cultura procedente de otro ámbito cultural que se dejó sentir durante un período de tiempo y que después, por la fuerza de la cultura tradicional latina, volvió a desaparecer con la misma facilidad que había aparecido.

Aquellas conclusiones me causaron sorpresa a la vez que un punto de satisfacción. Algunos lectores, a quienes agradezco la lectura y la atención prestadas, no se creyeron en conjunto aquellas observaciones gráficas; es de agradecer que fueran leales en manifestar su perplejidad, si bien hasta el presente no he visto que expusieran sus argumentos en defensa de sus dudas.

\section{UN AUTOR ILUSTRE Y UN ATENTO LECTOR}

Tenemos que proceder a presentar, aunque sea muy someramente, al menos, a dos personajes: uno en calidad de autor y otro por fiel trasmisor; la autoría corresponde a Enrique de Villena, y a Alvar Gómez de Castro la noticia conservada.

Don Enrique leyó mucho y cansó sus ojos en vigilias largas y continuas; ejercitó su memoria y aprendió mucho de los demás; elaboró unas ideas y como propias nos las trasmitió por medio de la escritura. Se pueden leer muchas de sus obras para deleite de aquellos que están interesados en los temas que se exponen en las páginas que se conservan ${ }^{2}$; otros, interesados en otros temas, por mor de la rigurosidad en el control de las ideas ${ }^{3}$, nos hemos quedado sin poder leer lo

1 CASADO QUINTANILLA, Blas, «Notas sobre la llamada letra de albalaes», en Espacio, Tiempo y Forma, Serie III, t. 9, págs. 327-345, y ver también «De la escritura de albalaes a la humanística, un paréntesis en la historia de la Escritura», en II Jornadas Científicas sobre documentación de la Corona de Castilla (siglos XIII-XV), organizadas y publicadas, por el Departamento de Ciencias y Técnicas Historiográficas. Universidad Complutense de Madrid, 2003, págs. 11-40.

2 VILLENA, Enrique de, Obras completas, Madrid, 1994.

${ }^{3}$ CUENCA MUÑOZ, Paloma, El 'Tratado de la Divinança' de Lope de Barrientos. La magia medieval en la visión de un obispo de Cuenca. Ayuntamiento de Cuenca, Cuenca, 1994. A la muerte de Enrique de Villena, año 1434, en la crónica de Juan II de Castilla, leemos que «el rey mandó que le fuesen traídos todos los libros que tenía, los cuales mandó que viese fray Lope de Barrientos, maestro del 
que nos hubiera producido gran deleite conocer. Fue Enrique de Villena un intelectual por vocación y llegó al maestrazgo de Calatrava con el apoyo de la Corona ${ }^{4}$. Maestre con más ilusión o frustración que acierto y con dudosa preparación para el cargo; nada más incorporarse al maestrazgo tuvo que enfrentarse a una oposición interna de algunos comendadores y caballeros defensores de sus preeminencias que le negaron la obediencia debida, según los Estatutos, y por añadidura sufrió la pobreza-riqueza de la Orden de Calatrava ${ }^{5}$.

Príncipe, e viese si había alguno de malas artes; e fray Lope lo miró e hizo quemar algunos e los otros quedaron en su poder», pág. 14.

${ }^{4}$ BONILLA, Luis, Historia de la hechicería y de las brujas, Biblioteca Nueva, Madrid, 1962, pág. 159163. Supone este autor que la quema de la biblioteca de Villena se había debido a una venganza póstuma por parte de Juan II de Castilla; y da esta explicación: Villena era un hombre de mucha personalidad, frente a un rey siempre rodeado de validos. Ya Enrique III había tenido problemas con Enrique de Villena; el rey obliga a Villena a contraer matrimonio con María de Albornoz, amante del rey y Villena desconocedor de estos amoríos regios; cuando Villena conoció este asunto repudia a su mujer y se enemista con el rey. A la muerte del maestre Gonzalo Núñez de Guzmán Enrique III obliga a los Calatravos a elegir a Villena como maestre de la Orden.

Según Sánchez Cantón, Villena era hijo de don Pedro de Aragón y doña Juana, hija bastarda de Enrique II de Castilla. Nació en 1384. Su padre murió en la batalla de Aljubarrota contra los portugueses; se fue a vivir con su abuelo Alfonso, marqués de Villena. Dice Sánchez Cantón que su abuelo lo quisiera para caballero, en su niñez; cuando los niños suelen por fuerza ser llevados a la escuela, él, contra voluntad de todos, se dispuso a aprender, e tan sotil e alto ingenio había, que ligeramente aprendía cualquier ciencia y arte a que se daba, así que bien parecía que lo había a natura.... Casó sin tener veinte años, con doña María de Albornoz, señora del Infantado, y, según la crónica de Juan II, «cuanto en uno duraron, siempre vivieron mal avenidos".

Continúa Sánchez Cantón afirmando en pág. 11 de la introducción que «prendado el rey Juan II de doña María, (mujer de Enrique de Villena) se amañó una bula papal para lograr el divorcio, alegando impotencia. Por dar apariencias legales a la infamia, entró doña María en Las Claras de Guadalajara, donde estuvo algunos días, más sin sujetarse a la regla. Compensó el rey a don Enrique forzando a la Orden de Calatrava que le eligiesen gran Maestre, siendo precisa una bula confirmando la sentencia de separación de los cónyuges; y para aceptar_el maestrazgo tuvo que renunciar al título condal, ¿de marqués de Villena?

Al morir el rey, en 1407, se encontró don Enrique Villena sin maestrazgo y sin condado, pero con... mujer, ipues desde Roma anularon el divorcio!» anteriormente concedido.

Se fue de nuevo para Aragón al amparo de su primo el rey Fernando de Antequera donde sobrevivió como mejor pudo. Murió el rey don Fernando en 1416; en 1417 doña Catalina le concedió el señorío de Iniesta; se retiró Enrique de Villena a sus tierras y empleó los años restantes de su vida en escribir y leer. Murió el día 15 de diciembre de 1434.

${ }_{5}^{5}$ VILLENA, Enrique de, Obras completas, t. I, Madrid, 1994, págs. 389-392. En estas páginas se publican unos documentos fechados en el año 1404 o 1405, todos firmados por Villena, maestre de Calatrava. Parece que el rey mandó al maestre de Calatrava pagar unos sueldos a la tropa que con él se había de reunir en Porcuna. El maestre Villena mandó dar la paga a los soldados, pero dice que «plege a vuestra merced de ordenar cómo yo les pueda acorrer con su sueldo con tiempo... sepa la vuestra señoría que bien podría tener más gente si tosiera manera con qué las pudiese sacar de sus casas; e si a la vuestra merced place que embie a por ellos, la vuestra merced me mande proveer por que lo yo cumpla ... yo enbiara luego por más gente si tosiera qué les dar para que pudieran venir...»

En el ámbito interno de la Orden también encontramos noticias que ahondan en la escasez dineraria. Así, después de la muerte del maestre predecesor de Villena en la Orden de Calatrava, mandó el rey que fueran embargados «los bienes que fueron e fincaron del maestre don Gonzalo Núñez de Guzmán...»; al mismo tiempo indicó a Villena que mandase procurador por el pleito sobre los bienes reclamados al maestre anterior. La respuesta de Villena al monarca demuestra la situación económica de la Orden al afirmar que se ha retrasado la presencia del procurador de la Institución «por quanto los maravedís que le eran necesarios de levar non los pude yo aver de presente, sobre los quales yo ove de embiar a Luis Méndez, mi recaudador, al Campo de Calatrava a los buscar prestados...», es decir, no hay un maravedí en el arca de la Orden. 
La diosa fortuna quiso que la vida de Enrique de Villena ${ }^{6}$ se desarrollara en paralelo con el reinado de Juan II, que «era, aunque mal rey, buen caballero, y muy aficionado a la Gaia ciencia ${ }^{7}$...»; esta situación de contemporaneidad es un elemento que ayuda a quien sabe ayudarse de las circunstancias propicias que provienen del poder político y, al mismo tiempo, conoce el camino para evitar las influencias adversas.

No nos interesa ahora el tiempo dedicado por Villena al maestrazgo de Calatrava. Nos ocuparemos de su faceta de estudioso y la destreza intelectual de don Enrique; podemos disfrutar de la lectura de varias de sus obras, y contamos con varios testimonios de sus coetáneos; unas y otros nos proporcionan un conocimiento de diversos aspectos de su personalidad:

Para Hernán Pérez de Guzmán, Enrique de Villena «... fue inclinado a las ciencias y artes más que a la caballería e aún a los negocios del mundo civiles ni curiales; ca no habiendo maestro para ello, ni alguno le costriñendo a aprender... quando los niños suelen por fuerza ser llevados a las escuelas, él contra voluntad de todos, se dispuso a aprender, e tan sotil e alto ingenio había que ligeramente aprendía cualquier ciencia y arte...

Era este don Enrique ageno y remoto no solamente a la caballería, más aún a los negocios del mundo y al regimiento de su casa e hacienda era tanto inhábile e inepto, que era gran maravilla. Se dio mucho a la astrología y por ello algunos burlando de él decían que sabía mucho del cielo e poco de la tierra.... e por esto fue habido en pequeña reputación de los reyes de su tiempo, y en poca reverencia de los caballeros.... ${ }^{8}$.

Con estas últimas palabras el autor parece entender, y así nos lo hacen creer, que entre los caballeros y entre los reyes lo de dedicarse al cultivo de la ciencia, en aquel tiempo, no era oficio loable entre los caballeros; es más, dedicarse al estudio era motivo de «burla» si no iba acompañado, además, de una dedicación a las armas y a la administración de la hacienda propia.

Al poeta Diego de Burgos la personalidad de Villena le merece un análisis muy elogioso y no duda en compararlo con personajes ilustres de su época:

«... El vno discípulo, el otro maestro,

Francisco Petrarca, que tanto escribió,

El otro Vocacio verás do los muestro;

Mira allí otro que en el reyno vuestro

6 VILLENA, Enrique de, Arte de Trovar, Madrid, 1923, edición, prólogo y notas de F.J. Sánchez Cantón. Crónica de Juan II de Castilla, BAE, LXVIII, pág. 279.

7 MARTÍN GAMERO, Antonio, Historia de la ciudad de Toledo, facsímil, t. II, Toledo, 1862, pág. 761

8 PÉREZ DE GUZMÁN, Fernán, Generaciones y Semblanzas, en Crónicas de los Reyes de Castilla, BAE, t. LXVIII, Madrid, 1953, pág. 710. 
Fue hombre notable, mas mal conoscido

Que dio a Villena ${ }^{9}$ famoso apellido;

Es don Enrique, más sabio que diestro».

Sánchez Cantón señala sobre Enrique de Villena, entre otras cosas, que «... en 1416 se retira a sus estados, ni grandes, ni pingües... quizás a recordar las desdichas de su vida cortesana y lo deslumbrador y fugaz de sus alegrías, buscando la causa de tantas mudanzas... No faltaba razón a Fernán Pérez de Guzmán, cuando escribía «era este don Enrique ajeno y remoto no solamente a la caballería, mas aún a los negocios del mundo; y al regimiento de su casa e hacienda era tanto inhábile e inepto, que era gran maravilla» ${ }^{10}$.

Y todavía añade que «... gran parte de las obras de magia se han perdido; queda El libro del aojamiento o fascinología (1425); las demás fueron quemadas por fray Lope de Barrientos, según confesión propia, por mandato de Juan II. El famoso auto de fe destruyó muchas obras de don Enrique, que, a creer a Juan de Mena, ni fray Lope leyó; cosa extraña, añade Sánchez Cantón, pues Barrientos era hombre curioso y hasta docto en tales disciplinas, por ser autor de las Especies de adivinanzas.

Conoció y estudió Francisco de Quevedo y Villegas la obra de Enrique de Villena ${ }^{11}$, y en concreto la Gaia Ciencia que nos ocupa la valoró de manera muy positiva: «Excelentísimo señor, en mi poder tengo un libro grande del infante don Enrique de Villena, manuscrito digno de grande estimación; infante a quien la ignorancia popular ha vuelto el túmulo de piedra que tiene su cuerpo en San Francisco desta corte, en redoma. Entre otras obras suyas de gran utilidad y elegancia, hay una de Gaya ciencia, que es el arte de escribir versos; doctrina y trabajo digno de admiración, por ver con cuanto cuidado en aquel tiempo se estudiaba la lengua castellana, $y$ el rigor y diligencia con que se pulían las palabras y se facilitaba la pronunciación cuando por mal acompañadas vocales sonaban ásperas $u$ eran equívocas $u$ dejativas a la lengua o al número, añadiendo y quitando letras; estudio de que no hay en otro libro noticia, y que sin ella mal se puede dar razón de las voces tan afectuosas de Las Partidas».

Además de estas afirmaciones muy elogiosas para Enrique de Villena y su obra, Quevedo ya dejó escrito aquello de que los «judíos ${ }^{12}$ habían infectado hasta nuestra forma de escribir las letras del Abecedario». Por tanto, participaba de la

9 BURGOS, Diego de, en Cancionero Castellano del siglo XV, ordenado por JR. Foulché Delbocs, t. II, Madrid, 1915, pág. 546.

${ }_{10}$ VILLENA, Enrique de, Arte de trovar, Edición, prólogo y notas de F. J. Sánchez Cantón, Madrid, 1923, págs. 12-13.

11 QUEVEDO Y VILLEGAS, Francisco de, Carta al conde-duque de Olivares, en Obras completas de.... Obras en prosa. Edición crítica de ASTRANA MARÍN, Luis, edit. Aguilar, Madrid, 1932, pág. 1587.

12 QUEVEDO Y VILLEGAS, Francisco de, España defendida, y los tiempos de ahora, de las calumnias de los noveleros y sediciosos, en Obras completas de... Obras en prosa, edición de ASTRANA MARÍN, Luis, Edit. Aguilar, Madrid, 1932, págs. 273-301. 
misma idea de que, en parte, nuestra forma de escribir las letras estaba contaminada de las culturas tanto «mora» al decir de Villena, como de la judía, al decir de Quevedo; en una y otra afirmación se atestigua la existencia e una influencia de las formas de las letras semíticas en las formas de las letras de nuestro abecedario; también podríamos pensar que parte del pensamiento de Quevedo acerca de la dependencia de la forma de las letras de nuestro abecedario y su relación con la cultura de los judíos, lo sacara Quevedo de los escritos de Villena en el Gaia ciencia, en otros pasajes de los escritos de Villena que por desgracia el fuego se llevó. No es más que una conjetura pero, ¿y por qué no pudo suceder así?

Enrique de Villena publicó su obra de Gaia Ciencia cuando ya había comenzado su andadura la denominada por sus usuarios letra cortesana. Una manera de escribir sorprendente en las formas que presentan algunas de las letras consonantes si procedemos a realizar un análisis comparativo con las formas que habían sido comunes en los años anteriores y con las formas que posteriormente adoptarán; no es de extrañar, por tanto, que autores como Enrique de Villena y otros de sus contemporáneos manifestaran su admiración y sorpresa por las formas gráficas que se enseñaban y se usaban en su tiempo. Sabemos por Alvar Gómez de Castro que Enrique de Villena dejó escrito que esas formas de las letras de la cortesana procedía de una imitación de las letras «moras»; también pudo dejar escrito que procedían de la imitación de algunas letras árabes o judías, aunque ese texto de Villena, lamentablemente, no ha llegado hasta nosotros, porque no lo copió Alvar Gómez de Castro, ni ningún otro autor.

\section{LAS CUESTIONES MÁS SEÑALADAS}

La obra Arte de Trovar de Enrique de Villena se perdió o, mejor, pereció a causa de la llamas en un auto de fe, como dijimos más arriba; lo que conocemos de la citada obra lo debemos «al humanista toledano del siglo XVI Alvar GÓMEZ DE CASTRO, en una obra conservada en la Biblioteca Nacional de Madrid y en la Biblioteca del Escorial» ${ }^{13}$.

«Era Alvar Gómez de Castro hombre erudito y curioso, incansable anotador de cuanto oía, leía o pensaba; y como su adoración por los clásicos iba acompañada de una grande afición a las cosas de la Edad Media, sus apuntes son fuente inagotable de noticias medievales. Este amor singular de los humanistas españoles a la Edad Media es uno de los rasgos distintivos, apenas señalado, de nuestro Renacimiento» ${ }^{14}$.

Sigue Sánchez Cantón ${ }^{15}$ señalando que «del estudio de otros extractos del humanista toledano se deduce que era fiel al copiar y de gusto extravagante al

13 SÁNCHEZ CANTÓN, F. J., pág. 31.

14 Ibídem, pág. 32.

15 Ibídem, págs. 36-37. 
elegir lo de más interés, y que, sin advertencia alguna, a veces interpolaba aclaraciones y notas de su propia Minerva, sin relación, al parecer, con lo que extractaba; por esto creo que en sus apuntamientos del Arte de trovar hay frases que nunca pensó escribir don Enrique de Villena; entre corchetes se imprimen aquellas que, a mi juicio, deben de ponerse en la cuenta de Alvar Gómez». Esta afirmación del editor importa mucho, porque las palabras que a nosotros nos interesan sobre la escritura cortesana no llevan corchetes; por tanto, son de Enrique de Villena.

\section{A. Las formas de las letras}

«La fecha ${ }^{16}$ del Arte de trovar, según él mismo nos declara, es la de 1433 ». No podemos dejar de señalar la importancia de la fecha en que se escribió esta obra. Unos años antes de que escribiera Enrique de Villena la obra que ahora nos interesa, ya los escribanos de la corte real escribían sus documentos con la letra denominada por la Corte castellana con el nombre de "cortesana» $y$ «apretada». En el citado año de 1433, se puede afirmar que estaba consolidado el uso de este tipo de letra.

Interesa destacar esa fecha tanto porque coincide con la generalización del uso de la letra cortesana, como porque en la citada fecha señala Enrique de Villena que existía un alfabeto de las letras que ha tenido un largo período de desarrollo a lo largo de los tiempos, y que nos reproduce Gómez de Castro de la manera que sigue:

«Después que la tierra se perdió en tiempo del rey don Rodrigo... recogidos los christianos en el monte sacro de Asturias, e perecieron los saberes entre ellos e aún el escribir y leer... desque fueron conquistando sintieron la mengua de la perdida letra e enviaron a la isla de Inglaterra por maestros que tuvieran escuelas de escribir y leer y gramática e mostráronles un tal alfabeto... e llamáronla letra anglicana...»

Hay que tener en cuenta que la palabra «anglicano» puede estar muy correctamente usada por Enrique de Villena, pues no faltan autores anteriores a Villena, ni coetáneos del autor, ni autores actuales que dicen que la letra que hoy nosotros denominamos «carolina» y que vinculamos a la corte de Carlomagno, según otros han afirmado procede de la reforma gráfica realizada en monasterios ingleses y no en centros monásticos franceses.

Para lo que hace al caso que nos ocupa mucho mayor interés revisten las palabras que reproducimos a continuación acerca del origen que se puede atribuir a las formas de algunas letras manuscritas usadas por algunos de los escribanos peninsulares del siglo XV, más en concreto los del reino de León y Castilla: «Toma-

16 SÁNCHEZ CANTÓN, F. J., pág. 38. 
ron de los moros las colas de las letras rebueltas, e el liamiento de los vocablos e tildes grandes, e el tener de la péndola, e el leer en son. Corrompióse el anglicano e vuo este [abecedario]

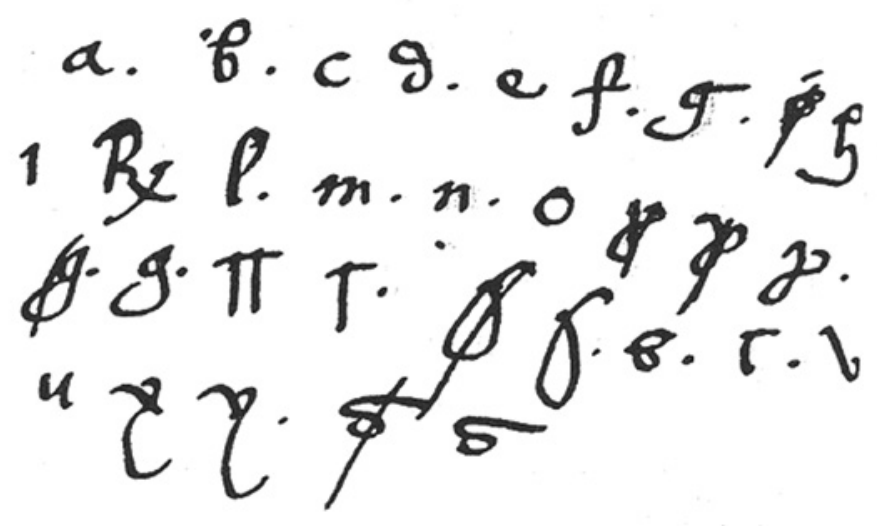

e este a llegado hasta el vso de este tiempo» ${ }^{17}$.

Villena destaca dos cuestiones en el análisis de las formas de las letras: «/etras enbueltas» y «el tener de la péñola». Si nos dice con claridad que las letras envueltas tienen su origen en una imitación de las grafía de los «moros»; nada se nos dice de a quien seguían nuestros escribanos «en el tener de la péñola», aunque bien podíamos deducir que tanto en una cosa como en la otra se imitaba no solo la forma de cortar la pluma, sino también la manera que usaban los escribanos árabes para coger la péñola para realizar la escritura.

Siguiendo con las afirmaciones de Villena observamos que tanto en lo que toca a los cambios de las formas de las letras envueltas como en lo que hace a la forma de sostener la péñola, se produjeron durante el reinado de Juan II de Castilla. Ello nos obliga a mirar muy atentamente a los personajes más influyentes de este reinado: de un lado, Salomón Ha Leví, el nombre hebreo de Pablo de Santa María, obispo de Burgos, con algo más de 23 años de edad abría en la citada ciudad de

17 DE VILLENA, Enrique, Arte de trovar, Edición, prólogo y notas de SÁNCHEZ CANTÓN,F. J., Madrid, 1923, págs. 74-75. VILLENA, Enrique de, Arte de trovar, Edición de F.J. Sánchez Cantón. Prospecto de Antonio Prieto, Madrid, 1993, págs. 74-75. VILLENA, Enrique de, Obras completas, I. Arte de trovar, Turner, Madrid, 1994, pág. 363.

Las reproducciones de las letras que nos ha copiado Alvar Gómez pueden ser consideradas como muy mejorables en todos los aspectos; sabemos por sus obras que don Alvar era un grande y muy meritorio intelectual; lo que no es obstáculo alguno para que en su información veamos cumplido aquello que se dice con harta frecuencia, y hasta con acierto, que no hubiera podido ganarse la vida como calígrafo. 
Burgos «una academia ${ }^{18}$ de estudios rabínicos, escriturarios y legales, y también de polémica contra el cristianismo, que le granjeó singular nombradía en toda la España hebrea, y el título de maestre general de los judíos españoles. A esta academia concurrieron jóvenes hebreos de toda la Península y bajo la dirección de don Pablo se formó la mayor parte de los rabinos, mayores y menores, que a finales del siglo XIV regentaban las aljamas de Castilla, Aragón y Valencia».

Toda su vida la había dedicado al estudio y por tanto dominaba perfectamente el hebreo y escribía perfectamente el hebreo y pensaba perfectamente en hebreo; su cultura era la hebrea, y reitero, escribía en hebreo, esto es, trazaba las letras según el ductus ordinario de las letras hebreas, comenzando por la derecha y finalizando por la izquierda del renglón, bien distinto, por no decir contrario, al ductus de la escritura latina. Así se pasó cuarenta años. Toda una vida.

El día 24 de diciembre de 1407 Enrique III hace testamento y entre sus cláusulas se afirma que «dexo por testamentarios a don Ruy López Dávalos, mi condestable, e a don Pablo, obispo de Cartagena, chanciller mayor del príncipe Juan, mi hijo ${ }^{19}$.

«Juan II nació en Toro el día 6 de marzo de 1405» y en este mismo año «don Pablo de Santamaría, el antiguo rabino, fue designado como uno de los maestros de Juan II» ${ }^{20}$. Más adelante, en el mismo testamento citado, en referencia a Pablo de Santa María afirma el rey que «quiero e mando que estos, y el obispo de Cartagena con ellos, el cual yo ordeno para la crianza y enseñamiento del dicho príncipe, tengan cargo de guardar y de regir e governar su persona del dicho príncipe mi hijo, hasta que él haya edad de quatorce años, e otrosí de regir su casa...».

No podemos dejar sin señalar la figura de Fernando Díaz de Toledo ${ }^{21}$, el referendario del rey. Fernando Díaz de Toledo fue: «auténtico cerebro gris del monarca en el terreno de la jurisprudencia. Este personaje, de origen judío converso, figura en la documentación como oficial a partir del año 1420 en calidad de bachalarius in decretibus. Su ascensión social también fue meteórica: un año más tarde, siendo todavía bachiller, suscribe documentos como Relator y Secretario». El 21 de febrero del año 1442 ya firma un documento como «doctor, oydor y referendario del rey». Y añade la autora «fue pues uno de los pocos incondicionales de Juan II, a quien sirvió hasta la muerte del monarca».

18 SERRANO Y PINEDA, Luciano, Don Pablo de Santa María, gran rabino y obispo de Burgos, Discurso de ingreso en la Real Academia de la Historia, Madrid, 1940, pág. 6.

19 LÓPEZ DE AYALA, Pedro, Crónica de Enrique III, BAE, t. LXVIII, Madrid, 1953, pág. 265.

20 SUÁREZ BILBAO, Fernando, Enrique III (1390-1406), Diputación Provincial de Palencia, Palencia, 1994, pág. 228.

21 RUIZ GARCÍA, Elisa, «La cultura escrita en tiempos de Juan II de Castilla», en Segundas jornadas científicas sobre documentación de la Corona de Castilla (siglos XIII-XV). Universidad Complutense de Madrid, Madrid, 2003, págs. 149-173. 
Otra persona de reconocida influencia, en todos los campos, durante el reinado de Juan II, es Álvaro de Luna, omnipotente político durante casi todo el reina$\mathrm{do}^{22}$, quien no puede estar muy lejos de este tema de la escritura, al menos en lo referente a las letras envueltas. Durante la minoría de edad de Juan II, en el año 1408, se dice que «Estando así en Guadalaxara el rey e la reyna, su madre, e las infantas y el infante don Fernando (futuro Fernando I de Aragón, por el compromiso de Caspe), hermano del rey don Enrique (III)... vinieron ende los grandes destos reynos... y el arzobispo de Toledo don Pedro de Luna había venido nuevamente de la Corte de Roma, porque el rey don Enrique nunca le había dado lugar que hubiese el arzobispado de Toledo, aunque estaba proveído de él, e traxo consigo a Álvaro de Luna ${ }^{23}$ que lo había allá llevado después de la muerte de su padre, un escudero, criado suyo, llamado Juan de Olio, de edad de siete años. Este Álvaro de Luna era hijo bastardo de Álvaro de Luna, Señor de Cañete (lugar cercano a Cuenca) e Jubera e Cornado, que era muy buen caballero y era copero mayor del rey don Enrique...

E cuando don Pedro de Luna vino en Castilla, tráxolo consigo, mozo de dieciocho años. E como el arzobispo tenía algún debdo con Gómez Carrillo de Cuenca, que era Ayo del rey don Juan, rogóle que lo tomase e lo pusiese en la cámara del rey don Juan; e así Álvaro de Luna hubo entrada en la casa del rey don Juan».

En estos años acusar a los judíos de todos los males o desgracias ocurridas, tanto de tipo político como social, era moneda común. No es de extrañar entonces que se achacara a Álvaro de Luna ser un destacado protector de los judíos y de los conversos y se le acusara expresamente de concederles siempre los oficios del reino en todos los ámbitos de aquella administración, también en lo que hace a las escribanías públicas ${ }^{24}$. Todavía queremos mencionar a Fernán López de Saldaña, otro personaje hechura de Álvaro de Luna, que ocupó unos cargos de mucha confianza y muy próximo a la persona del mismo rey Juan II ${ }^{25}$.

22 CAÑAS GÁLVEZ, Francisco de Paula, El itinerario de la corte de Juan Il de Castilla (1418-1454). Edit. Silex, Madrid, 2007. Crónica de don Álvaro de Luna, edic. de Juan de Mata Carriazo, Edit. Espasa Calpe. Colección de crónicas españolas, Madird 1940.

23 PÉREZ DE GUZMÁN, Fernán, Crónica de Juan I/ de Castilla, BAE, LXVIII, págs. 302-303.

24 MARTÍN GAMERO, Antonio, Historia de la ciudad de Toledo, Toledo, 1862, facsímil actual sin datación ni lugar de edición, t. II, págs. 1036-1040.

25 CEBALLOS-ESCALERA Y GILA, Alfonso de, «Generación y semblanza de Fernan López de Saldaña, contador Mayor de Juan II de Castilla», en Medievalismo, 21, 2011, págs. 161-206.

LÓPEZ DE SALDAÑA, Fernán (¿1400?- 1456), hijo de Nuño López de Saldaña, sevillano y converso, muy cercano a don Álvaro de Luna, el condestable, y valido de Juan II de Castilla y León. Fue un satélite de Álvaro de Luna, y un criado muy destacado del citado condestable desde muy temprana edad; no sabemos donde se conocieron, pero bien pudo ser en Toledo, cuando Álvaro de Luna estaba con su tío Pedro de Luna, arzobispo toledano.

Currículum de Fernán López de Saldaña, potenciado por Álvaro de Luna:

1. 422 , aparece como secretario del rey.

2. 1423 , le vemos como camarero del rey.

3. 1427, camarero de los «paños del rey», es decir, el encargado de cuidar y guardar los vestidos del «cuerpo» del rey, más las arcas e los escritos del rey Juan II. 
Lo cierto es que los judíos fueron expulsados en el año 1492, aunque los problemas venían siendo arrastrados desde antes de 1391. Los conversos, desde esta última fecha, habían aumentado de forma evidente ${ }^{26}$. Habrá que asumir, así mismo, que después de la terrible tempestad de 1391, llegó la calma, llegaron las conversiones voluntarias de los judíos, llegó la incorporación de muchos conversos o, directamente de muchos judíos, a la actividad intelectual del momento, sin que les podamos excluir también del mundo de la escrituración de los contratos entre particulares en calidad de escribanos públicos ${ }^{27}$, de los pleitos y de la literatura.

Desde finales del siglo XV la influencia, o la posible influencia de los conversos, en las formas de las letras consonantes de la escritura "cortesana», fue desapareciendo de nuestra forma latina de escribir. Para los años finales del siglo XV ya esta-

4. 1427, figura como escribano de Cámara y como «canciller» del rey.

5. 1429, contador mayor de «hacienda» de Castilla y León. [Sustituyó en el cargo a Fernán Alfonso de Robles, que como contador mayor fue destituido o cesado por el rey Juan II, por haber conspirado contra Álvaro de Luna en ese mismo año].

Secretario y Camarero del rey, Camarero de los paños del rey, escribano de cámara, canciller: todos son cargos de mucho proximidad a la persona física del rey y de cercanía con la actividad política diaria de la Corte; esto es lo que se puede decir estar todo el día con el rey. No cabe duda alguna que Álvaro de Luna le tenía de espía del rey o de todo lo que se moviera alrededor de la persona del rey las veinticuatro horas del día y la noche: desde que se levanta y se viste el rey (camarero de los paños) hasta que se acuesta: secretario, camarero (la despensa) escribano de cámara, canciller; en resumen, el espía.

6. 1431, ya con un gran patrimonio de bienes muebles e inmuebles: señor de pueblos y villas, el rey le concede autorización para constituir un mayorazgo.

7. Después de 1440 se le levanta un rumor contra él; el rey, a instancias de su protector Álvaro de Luna, le concede el perdón.

8. 1441, toma partido a favor de el Infante de Aragón, que era enemigo de Álvaro de Luna. Perdió la confianza de Álvaro de Luna y del rey. Fue preso en Castilla y después, salió de prisión, y con lo que pudo reunir de dinerario, se fue para Aragón, donde murió 1456; se le considera como uno de los más destacados traidores a Álvaro de Luna, que fue quien le promocionó desde el principio.

Nota final: Después de preso Fernán López de Saldaña, el cargo de «contador mayor de Hacienda» recayó en Alonso Álvarez de Toledo, también converso.

PÉREZ DE GUZMÁN, Fernán, en sus Generaciones y Semblanzas declara a Fernán López de Saldaña como "persona non grata», hasta el punto que se muestra muy enfadado porque los grandes de Casilla se sometieran a la voluntad de gente no noble que estaba en la Corte de Juan II, entre ellos Hernán Alonso Robles, «más vna liviana e pobre muger ansí como Leonor Lopez, e vn pequeño e raez hombre, Hernán López de Saldaña...

26 NETANYAHU, Benzion, Los marranos españoles según las fuentes hebreas de la época (siglos XIV-XVI). Traducción de Ciriaco Morón Arroyo. Junta de Castilla y León, Consejería de Turismo. Valladolid, 1994, págs. 106-109. Según este autor hay que considerar dos momentos distintos en la conversión de los judíos al cristianismo: uno, forzados por las persecuciones originadas en Castilla, sobre todo, en el año de 1391 y siguiente; y dos, las conversiones voluntarios de los judíos al cristianismo en los años 1412-1414. Este grupo de conversiones voluntarias se corresponden con los hijos de los que sufrieron las persecuciones. Las primeras conversiones fueron forzadas porque los judíos o huyeron o se escondieron o murieron o se convirtieron al cristianismo porque si no morirían; pero la siguiente generación comenzó a reflexionar que si ser judío llevaba consigo ser perseguido por los cristianos, y vivir en la miseria y en la pobreza y en la marginación social, mientras que convertirse al cristianismo suponía librarse de todos esos inconvenientes y poder prosperar en la sociedad, entonces decidieron abandonar el judaísmo y convertirse al cristianismo para prosperar en la sociedad, en su sociedad.

27 CASADO QUINTANILLA, Blas, "Nombramientos de escribanos públicos en Ávila, y sus circunstancias, en tiempos de los Reyes Católicos", en Espacio, Tiempo y Forma, Serie III, Ho Medieval, t. 17, 2004, págs. 115-129, en especial págs. 122-126, donde se trata el tema de los escribanos abulenses que habían incurrido en el delito de la «herética pravedad». 
ba en plena decadencia el uso de la escritura «cortesana» y ya había sido «infiltrada» de manera visible por las formas de las letras y de la escritura «humanística». La evolución posterior hacia las formas denominadas «procesadas» es objeto de capítulo aparte. ¿Pudo tener algo que ver la desaparición de los judíos de Castilla y León con la decadencia de la escritura cortesana en los citados reinos? Cuánto nos gustaría tener los datos necesarios para dar una respuesta acertada a esta pregunta.

Si nos situamos en el campo de la certeza histórica tendremos que asumir que a lo largo del siglo XV y, sobre todo, en la segunda mitad de este siglo, son muchos los peninsulares que se trasladan a cursar estudios a las universidades de Francia y de Italia, sobre todo a Bolonia. La mayor parte de estos estudiantes eran clérigos o aspirantes a clérigos. Allí aprendieron estos estudiantes el gusto por lo «renacentista», por el «humanismo», por el retorno a la cultura clásica latina; en lo que hace a la manera y a la forma de las letras, aprendieron el gusto por una escritura, sin las envolturas de nuestra cortesana, y por las formas de las letras como la «carolina» y los códices escritos en letra «carolina» que eran los más apreciados por los renacentistas italianos. Esos estudiantes peninsulares hispanos volvieron a la Península y se dedicaron a la enseñanza en las universidades hispanas o al ejercicio de sus diversos oficios en la sociedad, sin olvidar la abundancia de puestos de trabajo que lleva consigo la pujante Administración del Reino en el siglo XV. Las formas de las letras que aprendieron estos estudiantes en el ámbito renacentista europeo no guardaban relación con lo que conocían de sus respectivos lugares de origen hispano y lo que ellos habían aprendido en las escuelas en los tiempos de su mocedad. Paulatinamente transformaron su manera de escribir y se alejaron de las envolturas que caracterizaron a la «cortesana» para mostrar las formas de la escritura carolina en su renovada forma conforme al gusto de los humanistas.

La escritura cortesana, con sus formas envolventes, desaparece a finales del siglo XV o primeros años del siglo XVI, depende de cuál sea el ámbito geográfico peninsular objeto de estudio. Este lento proceso se va produciendo en la medida en que iban desapareciendo las personas que habían aprendido esta forma cortesana de escribir y eran sustituidas por otras personas, más jóvenes, que ya habían aprendido el arte de escribir con el modelo gráfico humanístico. Hay que anotar, también, que la escritura cortesana evoluciona hacia la denominada escritura «procesal» en el ámbito que le es propio, esto es, en el campo de los pleitos y procesos, donde se deteriora su forma y se endurece su lectura.

\section{B. El «tener de la péñola»}

En lo que hace a la cuestión del «tener de la péñola» a la que se refería Villena, y su influencia a la hora de tazar las letras, no podemos dejar de recordar las anotaciones realizadas por el humanista Antonio de Guevara, quien en repetidas ocasiones nos recuerda el tema y resalta su importancia: 
«Recibí una carta de vuestra señoría la cual, aunque no viniera firmada, la conociera en la letra ser de vuestra mano escrita, porque traía pocos renglones y muchos borrones. Agora que estáis en la guerra bien se sufre escribáis en papel grueso, los renglones tuertos, la tinta mala y la letra sucia y borrada, porque los guerreros más se precian de amolar las lanzas que de cortar las péñolas ${ }^{28}$ ».

Para este insigne humanista lo de «la letra sucia y borrada» tiene su origen en que no está bien cortada la péñola; la tinta mala se debe a que están en la guerra y los escribanos del ejército o los que se encargaran allí de preparar la tinta no son de los más expertos en su oficio de elaboración del contenido de los «tinteros».

Hablando Antonio de Guevara de sí mismo le dice a la señora destinataria que «siendo yo hijo de D. Beltrán de Guevara y sobrino de D. Ladrón de Guevara, a estar allá en el mundo [recordemos que era franciscano y vivía retirado en un monasterio] no había yo de escribir, sino de pelear; no de cortar la péñola, sino de aguzar la lanza;...29; cortar y manejar bien la péñola, para uno que se dedica a escribir, tiene la misma importancia que saber moverse con la lanza para uno que a la batalla dedica su tiempo. Se destaca una y otra vez el tema de la importancia de saber cortar bien la pluma para escribir con buena letra.

Todavía hablando de sí mismo y del arte de escribir afirma que «No se si lo hacía ser el papel grueso, o la tinta tener poca goma, o estar la pluma (sic) mal cortada, o estar yo en alguna desgracia, que a fe de cristiano le juro que comencé esta letra a escribir tres veces, y tantas las hube de borrar y aún rasgar. Acontéceme muchas veces que tengo la memoria tan fecunda y la elocuencia tan pronta, que con gran facilidad hallo lo que busco y digo lo que quiero; y por el contrario estoy otras veces conmigo tan amohinado y tengo el juicio tan remontado, que ni me agrada cosa que diga ni es digna de leer cosa que escriba...» ${ }^{30}$.

\section{OTROS TEMAS DE INTERÉS PALEOGRÁFICO}

Al rey corresponde hacer justicia y proveer en asuntos diversos de carácter político, militar o económico después de oír las opiniones respectivas de los miembros de su Consejo; a otros muchos toca escribir aquellos acuerdos y las órdenes emanadas de la Corona y de la Corte. Los encargados por oficio de poner por escrito las decisiones administrativas, esto es los escribanos de aquella época, ejercerán su oficio usando una u otra forma gráfica, dependiendo de los tiempos históricos y su evolución. Algunos de estos amanuenses conocieron directa o indirectamente las enseñanzas que Enrique de Villena fue exponiendo en su Arte de

28 GUEVARA, Antonio de, Epístolas familiares, Edit. Espasa-Calpe, Madrid, 1941, letra núm. II, pág. 21., en Carta al condestable Íñigo de Velasco.

${ }_{29}$ Ibídem, letra núm. 47, pág. 113. Letra para María de Padilla, mujer de Juan de Padilla, capitán comunero de Castilla.

30 Ibídem, letra núm. XI, pág. 144. Letra para el ilustre mancebo Francisco Manrique. 
trovar «sobre prosodia y ortografía castellanas, con una curiosa atención al origen de las letras y su historia... ${ }^{31}$; otros no llegaron a conocer las ideas expuestas por nuestro autor.

El infante de Aragón, don Enrique de Villena, además de todo lo expuesto hasta ahora, nos dejó, según Alvar Gómez de Castro, otras anotaciones que el ilustre humanista copió de la obra de Villena y que son de gran interés para la correcta lectura y transcripción de los textos manuscritos procedentes del siglo XV. Comencemos por las palabras en cuya composición entran determinadas letras como la «r»y la «ñn»:

"Cuando la ' $r$ ' es semisonate no se dobla: ara, ira; quando es plenisonante dóblase: error. En principio de dicción es plenisonante, no se dobla: rey, Roque, roçín; en los nombres propios, en medio de dicción es plenisonante y no se dobla: Enrique, Fernando...».

Por su parte. Nebrija ${ }^{32}$ señala que «de donde se comete el error de los que escriven con doblada «r», rrei, en el comienzo, y en el medio onrra».

Si nuestro interés se ocupa de conocer en qué momento se ha introducido en la escritura el uso de la letra «ñn y su consecuencia inmediata de usarla nosotros de manera correcta para los transcripciones de los documentos de la época, basta con leer atentamente lo escrito por $\mathrm{Nebrija}^{33}$ al respecto:

«La n tiene dos fuerças, una que traxo consigo del latín et otra que le damos agena, doblandola et poniendo encima la tilde, más dexando la $\mathrm{n}$ sencilla en su fuerça para representar aquel son que le queremos dar prestado ponermos una tilde encima o haremos lo que es esta pronunciación hazen los griegos e latinos escriviendola con gn como quiera que la n con la g se hagan adulterinas et falsas».

«La n doblada pasa en aquella boz que diríamos que se avía de escribir con gn como de annus, año, de pannus, paño».

Juan de Valdés (Cuenca, ca. 1494-1541) en sus Diálogos de la Lengua ${ }^{34}$ escritos en el año de 1535, critica en varias ocasiones a Nebrija por considerar que este autor es un andaluz que a la hora de escribir su Gramática, publicada

\footnotetext{
31 VILLENA, Enrique de, Arte de trovar, Edición de F.J. Sánchez Cantón. Prospecto de Antonio Prieto, Madrid, 1993, Visor Libros, pág. XVII y 79.

32 NEBRIJA, Antonio de, Gramática castellana, Junta del Centenario, edición preparado por GALINDO ROMERO, Pascual, y ORTIZ MUÑOZ, Luis, Madrid, 1946, pág. 34.

33 ID, págs. 25 y 28.

34 VALDES, Juan de, Diálogo de la lengua, en Obras Completas, I, Madrid, 1997, Biblioteca Castro, págs. 151-266.

DEL PULGAR, Hernando, Claros varones de Castilla, Facsímil de la edición de Sevilla, el 24 de abril de 1500. Importa mucho este dato de que sea una edición facsímil porque el editor escribió en esa fecha determinadas palabras de una forma muy interesante: «año», «señor», «señorío», «España», «constriñó», «dañan»; todas con «ñn.
} 
en 1492, siempre se expresa con la forma de escribir y, por tanto, de pronunciar el castellano en Andalucía.

En muy partidario Juan de Valdés de usar los refranes castellanos para apoyar sus tesis acerca de las más variadas cuestiones gramaticales, ortográficas y de vocabulario castellanos.

La lengua Castellana ${ }^{35}$ «confórmase también con el latín en el abc, aunque difiere en esto, que la legua castellana tiene una j larga que vale por gi, y tiene una que nosotros llamamos cerilla la cual haze que la c valga por z. Tiene más una tilde que en muchas partes puesta sobre la $\mathrm{n}$ vale tanto como g. .... de manera que según eso podremos bien dezir que el abc de la lengua castellana tiene tres letras más que el de la latina».

A lo que vemos, en tiempos de Juan Valdés, esto es, a principios del siglo XVI, ya existían estas tres letras de uso general entre los entendidos, y era lo que se explicaba en las aulas universitarias: la jota, con valor de jota; la ç, con pronunciación y acaso valor de zeta, y la eñe procedente tanto del grupo gn= ñ, como del grupo ene más ene $=\mathrm{nn}$ con tilde igual a $\tilde{n}$.

Insiste Valdés ${ }^{36}$ en el asunto de la «ñn», «porque la lengua castellana no conoce de ninguna manera aquella pronunciación de la g con la $\mathrm{n}, y$ veréislo porque no dize segnor, sino señor, sirviéndose de la tilde adonde vosotros os servir de la $\mathrm{g}$, de manera que quando yo quisiesse que el castellano pronunciase como vosotros el manífico y el sinifico, pornía en lugar de vuestra g nuestra tilde, como hago en iñorancia, $y$ diría mañífico y siñifico».

"Quanto a la cerilla ${ }^{37}$ (cedilla) que es una señaleja que ponemos a algunos vocablos debajo de la c, digo que pienso pudo ser que la c con la cerilla antiguamente fuesen una z entera... Lo que importa es dezir que la cerilla se ha de poner quando, juntándose la c con la a, con la o y con la u, el sonido ha de ser espesso, diziendo çapato, coraçón, açucar... Y quando se junta con la e y con la i, para dezir cecear y cimiento... no se ha de poner, porque con cerilla o sin ella siempre pronunciáis estos vocablos y los semejantes a ellos de una mesma manera, pués pudiéndonos ahorrar la cerilla, indiscreción seria ponerlo.»

«... la tilde generalmente sirve en castellano del mismo oficio que en el latín, y particularmente puesta sobre la $\mathrm{n}$ vale lo que al latino y toscano la g quando está cabo la n, y asi donde el toscano escribe signor el castellano pone señor "... de la misma manera creo aya acontecido en daño y año y en algunos otros adonde primero valía la tilde lo que en el latín diziendo dañun y añum ${ }^{38}$...»

\footnotetext{
35 VALDÉS, Juan de, op. cit., pág. 174.

VALDÉS, Juan de, op. cit., pág. 197.

7 VALDÉS, Juan de, op. cit,. pág. 207.

38 VALDÉS, Juan de, op. cit,. pág. 208 ( ver también 174 y 197).
} 
En su obra Diálogo de la lengua, Valdés, de forma imaginaria, da entrada a algunos discípulos o a los alumnos más curiosos que formulan preguntas relacionadas con determinados signos gráficos cuyo significado ignoraban ellos, e incluso, podemos desconocer nosotros:

«Pregunta del alumno: ¿de qué sirve la tilde sobre como y sobre muy?

Respuesta de Valdés: solamente se pone por adorno de escritura.

Pregunta ¿y un rasguillo que ponéis delante de la o?

Respuesta: De lo mesmo.

Pregunta: De manera que quien lo dexase de poner ¿no gastaría la sentencia?

Respuesta: No, de ninguna manera ${ }^{39} .{ }^{\prime}$

Queremos fijar la atención un momento en este tema. Todo apunta a que hubo un tiempo en el que alguna dificultad o cuestión acompañaba a los hombres del siglo XV y XVI relacionada con la «r» y la «rr»; no es fácil pasar por alto que, incluso, un humanista del siglo XVI como Alvar Gómez de Castro, le llamara la atención, como vimos más arriba, esta afirmación de Villena relacionada con la letra «r», y lo copie en sus notas o apuntes tras la lectura de su obra; el tema tenía su interés para un atento lector humanista y lo conserva para nosotros en la actualidad por su utilidad para hacer una lectura más correcta de los manuscritos de la época que estudiamos.

Villena, además, relaciona el uso de una «r» o de dos «rr» con el «sonido» de la letra en la pronunciación y con la escritura y señala que depende de su posición para ser o tener un sonido $u$ otro, y una forma de escribir u otra. ¿Por qué tenían que insistir tanto en este tema y además de una forma tan tajante: se dobla, no se dobla a la hora de escribirla?

Vemos, en cambio, como hablando del uso de otras letras no se muestra tan tajante en sus aseveraciones: «la $\mathrm{m}$ e la $\mathrm{n}$ conuienen en son algunas vezes en medio de dicción, así como diziendo tiempo, que aunque se escribe con $\mathrm{m}$ faze son de $\mathrm{n}$; e si lo escriben con $\mathrm{m}$ faze el mismo son, e por eso algunos lo escriben con $\mathrm{n}$ auiéndose de escreuir con $\mathrm{m}$ ».

Recoge Alvar Gómez de la obra de Villena algo que también le ha llamado la atención: "Las letras mutas ${ }^{40}$ (mudas) son nueve: $b, c, d, f, g, k, p, q, t, \ldots$ las semivocales son çinco: $I, m, n, r, s$ ». Esta cuestión de las letras consonantes mudas y semivocales tiene mucho interés y está muy relacionada con la explicación que se ha de dar a gran parte de las abreviaturas con las que nos encontramos en los documentos y en los códices.

39 VALDES, Juan de, op. cit., pág. 209.

40 VILLENA, Enrique de, Arte de trovar, edición, prólogo y notas de Sánchez Cantón, Madrid, 1923, pág. 81 . 
Y aún guarda relación con «algunas letras que se ponen e non se pronunçian ${ }^{41}$. Así, señala Villena que «la e, cuando viene después de muda, no suena sino el son de la muda, porque termina en ella. Así como be, que faze son de b e se encubre con la e. E esto acaeçe porque en el leer no se pone letra pronunçiada por sí, sino copulada con otra, salvo las vocales, que se ponen en algún lugar por sí...». Esta doctrina aplicada a las palabras abreviadas ${ }^{42}$ nos da como resultado que son muchas las sílabas que sólo eliminan la letra «e».

\section{CONCLUSIONES}

El intelectual Enrique de Villena se ocupó de muchas cosas en sus escritos. Otros han leído los temas que les han interesado para sus estudios; nosotros recogemos aquí lo que toca a las anotaciones de interés paleográfico. El «fuego»se llevó para siempre la obra de "Arte de trovar» en la que Villena dejó constancia de su preocupación, entre otras cosas, por algunos temas que hacen a las formas de las letras, a su origen y a la importancia del «cortar de la péñola» en el arte de trazar las letras de nuestro abecedario. Conocemos algunos de los párrafos de su obra porque Alvar Gómez de Castro, ilustre humanista, copió parte de las afirmaciones que escribió Villena en la citada y perdida obra. Por esta vía llegamos nosotros a conocer que la escritura denominada por la corte castellana con el nombre de «cortesana» y usada por nuestros antelados durante el siglo XV, tiene una gran influencia de la cultura gráfica de «los moros» en la forma de las letras.

Se ocupó Villena, y también otros intelectuales del siglo XV y primeros años del siglo siguiente, de cuestiones que hace al caso conocer para hacer una lectura correcta de los manuscritos de los citados siglos en la que toca al uso de letras como la «r», sencilla, la «rr», doble, al principio o en medio de la palabra, y su respectiva pronunciación; o la incorporación de la «ñn y la «j» a la escritura de la época; o la importancia que acompaña a las letras «consonantes» a la hora de interpretar ciertas abreviaturas; o la introducción de signos en la escritura que no tienen otro valor que el de simples adornos gráficos.

41 VILLENA, Enrique de, Obras completas, I, Libro de la Sciencia Gaya (págs. 353-370), Turner, Madrid, 1994, pág. 366.

42 CASADO QUINTANILLA, Blas, Paleografía. Nociones básicas para leer documentos conservados en los archivos históricos. CSIC, CECEL, Madrid, 2013, págs. 13-24. Ver las páginas dedicadas al estudio de las abreviaturas. 
